\title{
EVALUATION OF USING MODAL TESTING FOR DAMAGE DETECTION IN MASONRY ARCHED BARRAGES
}

\author{
AHMED M. ANWAR ${ }^{1}$, AHMED S. HASHAD ${ }^{2}$ \\ ${ }^{1}$ Researcher, Construction Research Institute, National Water Research \\ Center, Egypt \\ ${ }^{2}$ Associate Professor, Construction Research Institute, National Water Research \\ Center, Egypt
}

\begin{abstract}
Modal testing is widely used as a fast and effective tool for structural health monitoring and damage assessment. Old masonry barrages are characterized with their massive and rigid nature. Nevertheless, the complex material configurations make it difficult to be investigated and/or evaluated. This paper examined the ability and the constrains of using modal testing technique with masonry arches considering sensitivity and practicality. Masonry arches of a semi-circular shape with different stiffness and damage conditions were prepared and examined experimentally under static and dynamic tests. The dynamic characteristics for each condition were evaluated. A sound arch was degraded in two manners, the first by decreasing its thickness, while the other by applying severe crack experimentally. Additionally, Numerical investigation was conducted to simulate arches with different damage severities. Finite Element Model was calibrated using the material properties results obtained experimentally. The results of numerical study were compared with the experimental results to investigate the practicality and sensitivity of this technique. It has been noticed that the modal analysis testing can be used with masonry arches to determine any degradation occurred in arches. It is however; found that the technique was not powerful in identifying the reason behind this degradation. Moreover, correlation between the change in fundamental natural frequency and the corresponding reduction in stiffness was investigated.
\end{abstract}

\section{Keywords:}

Masonry Arches, Modal Testing, Damage Detection, Static Loading, Dynamic Testing.

\section{INTRODUCTION}

Barrages are considered one of the most important irrigation structures in Egypt. Arches are the common structural system used in the superstructure portion of old masonry barrages. Most of these barrages have been built many years ago using masonry bricks and they are still in service till now. The construction cost of new reinforced concrete barrages is very expensive and might be subjected to corrosion problems. Thus, it is of great importance to keep them working functionally by applying suitable way of not destructive evaluation. The current study introduces a technique for damage detection that could be considered a part of health monitoring program for these types of structures.

The arches of barrages may be found in deep need for repair and/or retrofitting due to aging and environmental problems. Moreover, mechanical damage, overloading, overstress due to temperature changes, or harsh environmental exposure, material weathering, seismic loading and foundation differential settlement are among the main reasons for deterioration. Figure 1 displays common damage patterns in arches.

Although there are several methods used to evaluate structural capacity, it is urgently need to develop a reliable method that could be used to identify and or 
evaluate the integrity of these sophisticated types of structures.

The modal testing technique provides a direct way to obtain the real dynamic properties of structures. The modal testing is considered as a non-destructive evaluation technique and has been successfully applied to various types of structures as per Salawu and Clive [1]. They used the modal analysis to evaluate the repair works of a bridge. The results showed that the mode shapes gave good indications of the presence of repair and its location. Armstrong et al. [2] used the dynamic stiffness technique based on the frequency response function (FRF) to investigate the integrity of masonry arches and to study the effect of fill material and applied loading on their structural properties. The excitation force used was impact hammer and the displacement response were measured using accelerometer and geophone. Paultre et al. [3] used dynamic testing technique on a series of highway bridges to study the effect of structure strengthening on the dynamic properties. The results showed that the natural frequencies were increased due to bridge strengthening. Modal testing technique was used in many researches to assess the repair works of different structures [4 \& 5], also this technique was used in the seismic evaluation of bridges [6].

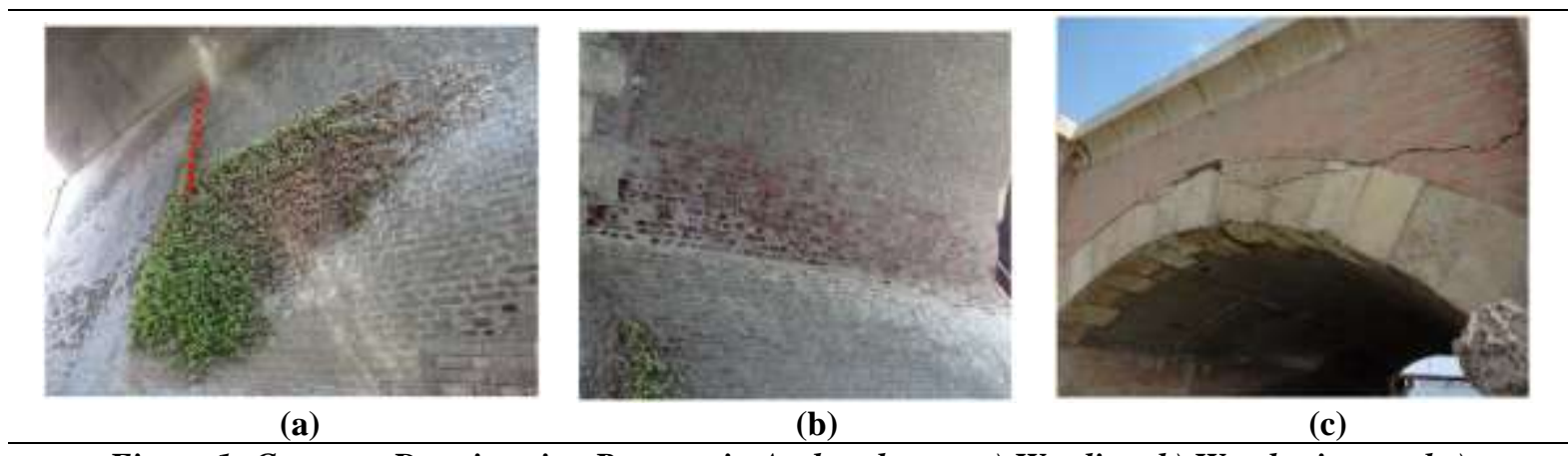

Figure 1: Common Deterioration Patterns in Arches due to: a) Weeding, b) Weathering, and c) Overstressing

Calik et al. [7] identified the dynamic characteristics of the masonry vault before and after repair, using steel fasteners at the peak of vaults. Bayraktar et al. [8] conducted formal modal analysis on eight historical masonry stone arch bridges with different spans to determine their natural frequencies, damping ratios and mode shapes. The dynamic behavior and modal parameters of brick masonry arches strengthened with prepreg polymer composites were experimentally and numerically studied by Cakir and Uysal [9]. Xie et al. [10] used CFRP to strengthen a concrete buried arch against blast applied at its soffit surface only.

The current research presents an investigation to accommodate the modal testing technique to examine and predict the deduction in overall stiffness of masonry arches with their sophisticated nature. The dynamic properties of the masonry arches, mode shapes and frequencies were determined by dynamic modal testing before and after subjecting to damage. Numerical models were also prepared and calibrated with the experimental results to validate the results and were used for parametric study by applying further damage patterns and levels.

\section{EXPERIMENTAL PROGRAM}

\subsection{Arches Preparation}

In the current work, masonry arches of a semi-circle shape were prepared for experimental investigation. The arches were composed of red clayey solid brick 
units bonded together with cement mortar. At the beginning, two main arches were identically prepared. In order to simulate different stiffness levels for both arches; a layer of plain concrete of thickness $50 \mathrm{~mm}$ was casted above one of the masonry arches. Furthermore, unidirectional sheets of Carbon Fiber Reinforced Polymer (CFRP) were added at the intrados and extrados surfaces of this arch. In fact, this arch will be used as a control specimen (hereinafter referred to as "S-Arch-CFRPConc") - Figure 2. Whereas, the second specimen will be used as an arch with reduced stiffness (hereinafter referred to as "S-Arch") - Figure 3. The aim of using CFRP sheets was to prevent the full collapse that might be expected when the arch was subjected to severe damage.

Table 1: Physical Properties of used Materials

\begin{tabular}{|c|c|c|c|c|}
\hline Type of Specimens & $\begin{array}{c}\text { Unit Weight } \\
\left(\mathrm{KN} / \mathrm{m}^{3}\right)\end{array}$ & $\begin{array}{c}\text { Compressive Strength } \\
\left(\mathrm{N} / \mathbf{m m}^{2}\right)\end{array}$ & $\begin{array}{c}\text { Flexure Strength } \\
\left(\mathrm{N} / \mathbf{m m}^{2}\right)\end{array}$ & $\begin{array}{c}\text { Indirect Tensile } \\
\text { Strength } \\
\left(\mathbf{N} / \mathbf{m m}^{2}\right)\end{array}$ \\
\hline Clayey Bricks & 21.0 & 3.5 & 0.7 & -- \\
\hline Cement Mortar & 22.5 & 15.0 & 2.5 & 1.3 \\
\hline Plain Concrete & 23.1 & 23.0 & 2.9 & 2.1 \\
\hline
\end{tabular}

\subsection{Materials}

In this research, the physical and mechanical properties of all the components used for constitution of arches were examined experimentally. The bricks were of dimensions (length $\mathrm{x}$ width $\mathrm{x}$ thickness) equal to (180 x $80 \times 60 \mathrm{~mm})$. The average binding mortar thickness was $10 \mathrm{~mm}$. In the current research, masonry arches constituted of red clayey solid brick units bonded together with cement mortar. The compressive strength test was conducted on one unit of bricks laid horizontally, whereas, a mortar cube of dimensions $(70 \times 70 \times 70 \mathrm{~mm})$ was used for this purpose. The flexure strength was determined by adopting four points load test on one brick unit. While mortar specimens of dimensions $(160 \times 40 \times 40$ $\mathrm{mm}$ ) were used for both flexure and splitting tests. For the purpose of strengthening, sheets of CFRP as well as a layer of plain concrete (P.C.) of $50 \mathrm{~mm}$ thickness were used. Uni-directional CFRP sheets, $0.111 \mathrm{~mm}$ thickness was used. As per the manufacturer, the tensile strength, and modulus of elasticity of CFRP are $3400 \mathrm{~N} / \mathrm{mm}^{2}$, and $2.45 \times 10^{5} \mathrm{~N} / \mathrm{mm}^{2}$, respectively. CFRP was pasted on the required surfaces using two compounds epoxy recommended and supplied by manufacturer. For plain concrete, cylinders of diameter, $100 \mathrm{~mm}$, and height, $200 \mathrm{~mm}$, were prepared for compression and splitting tests. Whereas, prisms of dimensions $(500 \times 100 \times 100 \mathrm{~mm})$ were set for four points flexure tests. Table 1 shows the physical properties of the used materials.

\subsection{Test Setup}

Both arches were first subjected to dynamic modal testing. The dynamic characterization at their sound state was identified for both cases. Acceleration time histories, in the vertical direction, were collected at the crest of the arches due to an impact by a light mass hummer. The arches were then subjected to static loading by applying a concentrated load vertically at the crests of the arches. The loading was stopped at a deflection value of $(0.12 \mathrm{~mm})$. This value was found reasonable not to cause any cracks in either arches. The linear static behavior for the load deflection curves for both arches was used for stiffness calculation. The static loading was again resumed till failure occurred. For (S-Arch), the arched specimen was 
totally collapsed at peak load. Whereas, (SArch-CFRP-Conc) reached the peak loading capacity without complete distortion due to the presence of CFRP sheets. The damaged arch (hereinafter referred to as "S-Arch-CFRP-ConcDamage") was finally examined in a dynamic fashion to determine the change in its modal parameters. The current static stiffness value and the degree of degradation of (S-Arch-CFRP-ConcDamage) were determined by reloading till a deflection value of $(0.12 \mathrm{~mm})$. For all arches, a rectangular plane frame consisted of steel angles [L50x50x5 mm] was used to prevent the horizontal movement at the base of the arches during testing.

\section{SYNTHETIC}

\section{EVALUATION}

\subsection{Numerical Models}

Set of Finite Element Models (FEM) were built to simulate different cases of damage. These (FEM) were subjected to static and dynamic analysis to determine the restoring rigidity and the corresponding fundamental frequency for each case. First, damaged cases similar to those adopted in the experimental work were investigated. Three extra trials simulating the reduction of the arch stiffness due to some common patterns of damage were also focused.

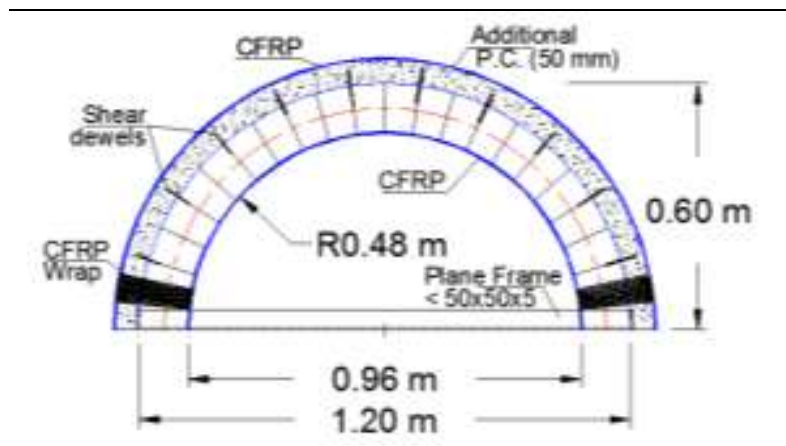

Figure 2: Configuration of the Control Arch (SArch-CFRP-Conc)

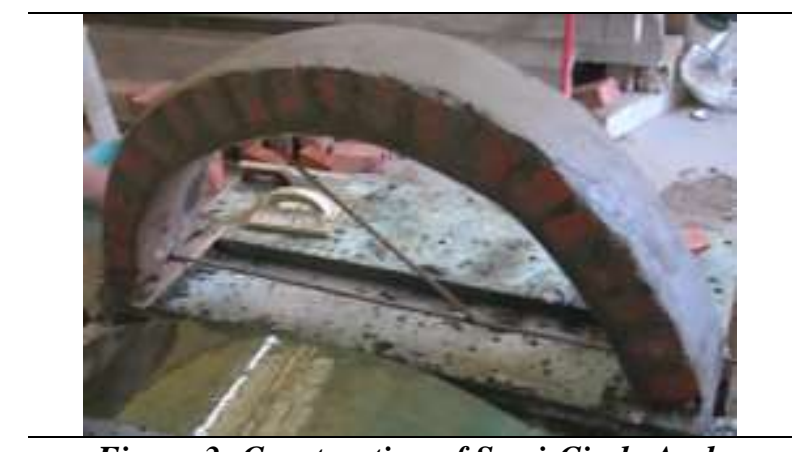

Figure 3: Construction of Semi-Circle Arch (S-Arch)

The commercially used SAP2000 Package [11] was chosen to create the 3D (FEM). The arch body was molded by using solid elements, while the arch supports were modeled using two adjacent hinged supports at each side. The defined material properties considered in the analysis (The modulus of elasticity, passion ratio, allowable compressive strength) were obtained from experimental material tests as defined above. The masses were calculated from the own weights of the actual cross section of the elements. Figure 4, shows the (FEM) for the masonry arch.

The solid elements that represent the arch body were meshed to fine units to give the ability to remove some solid elements to reach to any thickness to represent the occurred damage in the model in the cases of global its stiffness reduction or to remove any elements that could represent the cases of local damage. Although, five levels of damage were considered the arch total mass was kept constant during all the damage cases as the original one. 


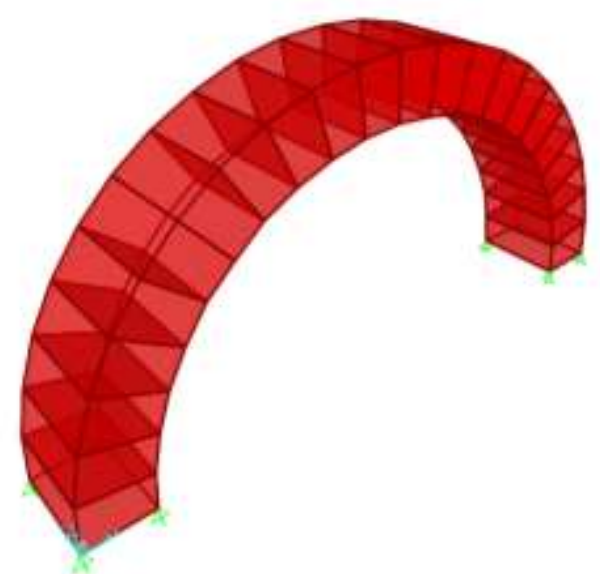

Figure 4: Finite Element Model for the Masonry Arch

Three damage locations were considered as displayed in Figure 5 to study the effect of damage location. The size of damage was the same in the three cases.

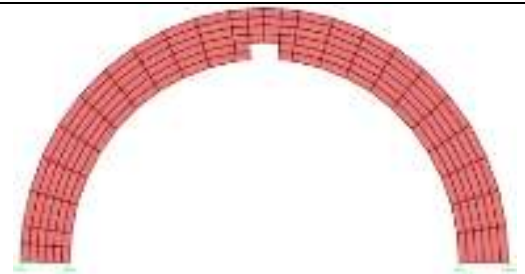

a) Damage in key

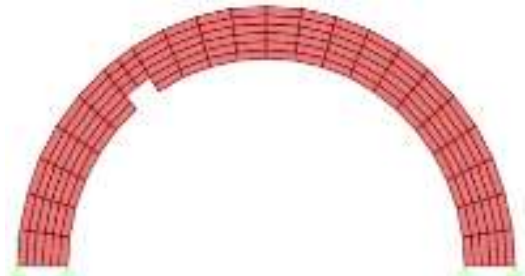

b) Damage in Quarter Span

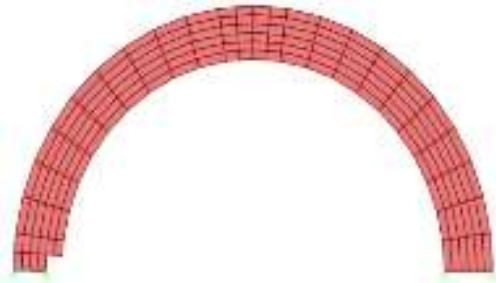

(C) Damage near Support

Figure 5: Different Damage Scenarios used in FEM

For each model, the global stiffness was estimated as a relative value to the original control arch. The relative stiffness was calculated from the ratio between the value of deflection at the middle point of the arch for any damage case and the undamaged one under the effect of the same load value. The dynamic analyses were performed to get the mode shapes and the natural frequencies. Figure 6 shows the considered mode shape in this study. The considered mode was selected to match with the experimentally measured one.

\section{RESULTS AND DISCUSSION}

\subsection{Experimental}

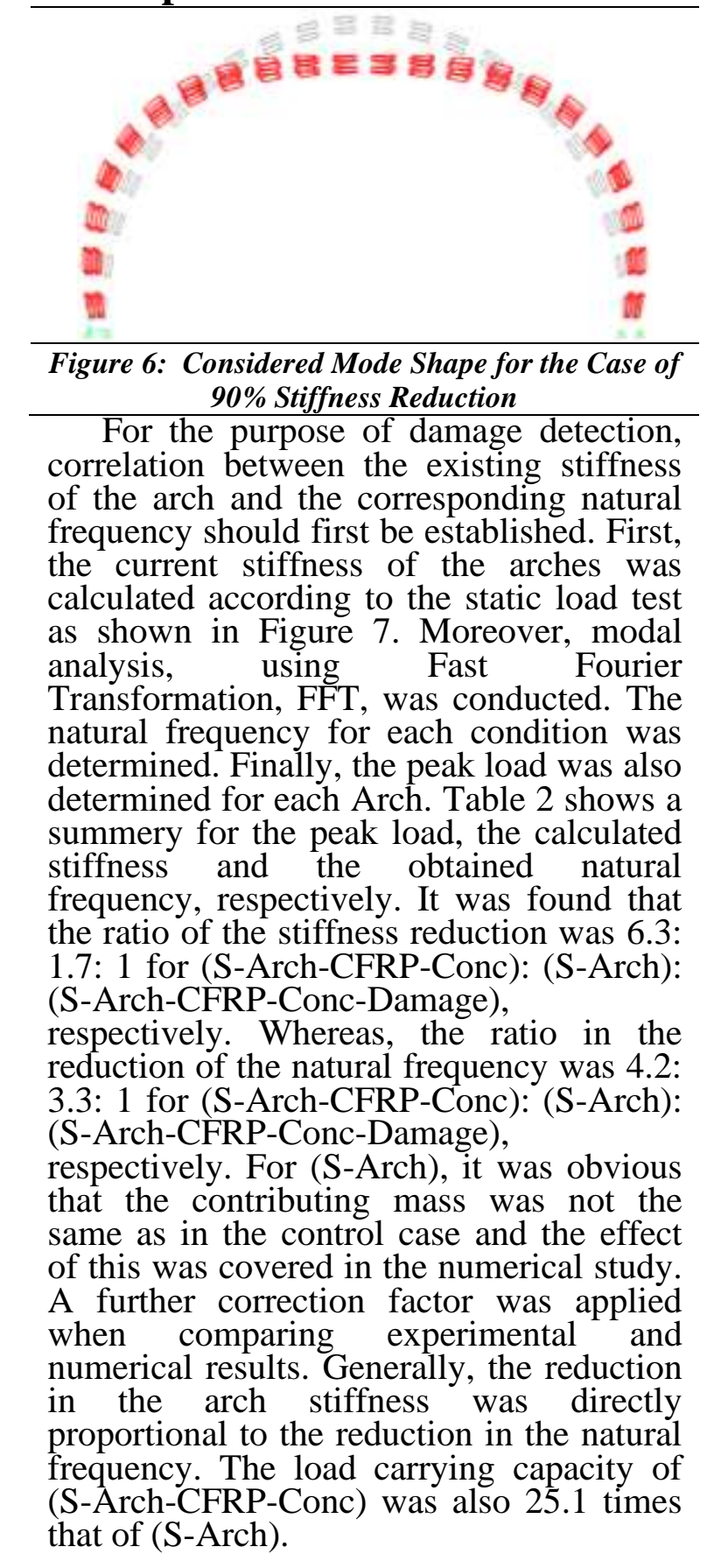




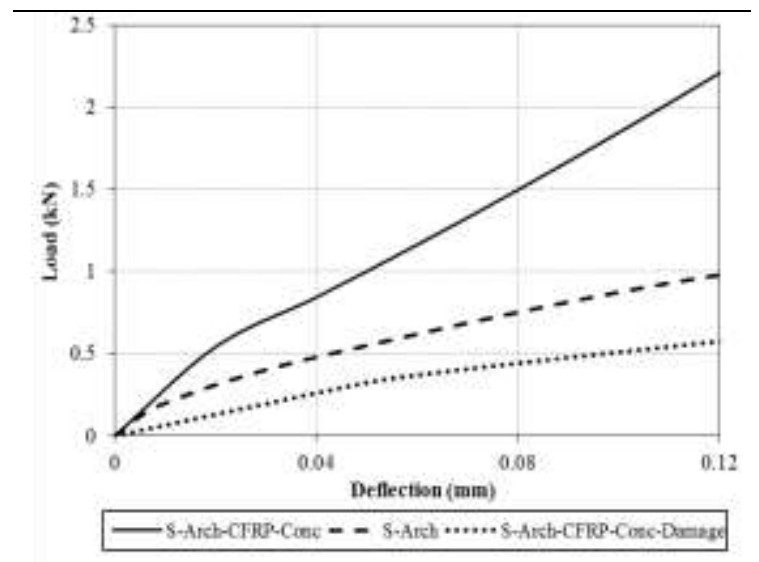

Figure 7: Behavior of Load-Deflection Curves for All Arches at Early Stage

Table 2: Properties of the Examined Arches

\begin{tabular}{|c|c|c|c|}
\hline & $\begin{array}{c}\text { S-Arch- } \\
\text { CFRP- } \\
\text { Conc }\end{array}$ & S-Arch & $\begin{array}{c}\text { S-Arch-CFRP- } \\
\text { Conc-Damage }\end{array}$ \\
\hline $\begin{array}{c}\text { Failure Load } \\
\text { (KN) }\end{array}$ & 42.10 & 1.68 & -- \\
\hline $\begin{array}{c}\text { Calculated } \\
\text { Stiffness } \\
\text { (KN/mm) }\end{array}$ & 23.34 & 6.25 & 3.68 \\
\hline $\begin{array}{c}\text { Natural } \\
\text { Frequency } \\
\text { (Hz.) }\end{array}$ & 263.67 & 209.96 & 63.48 \\
\hline
\end{tabular}

Acceleration -Time histories along with the corresponding Fourier spectrum for all specimens were plotted to facilitate the comparison of their natural frequencies. Figure $8 \mathrm{a}, \mathrm{b}$, and $\mathrm{c}$ show the shape of specimens (S-Arch-CFRP-Conc), (S-Arch), and (S-Arch-CFRP-ConcDamage), their time histories, and FFT, respectively. It was also clear from the graphs that the damping ratio of the damaged sample was higher than the other two arches. This could also be a way to identify the source of the reduction in natural frequency of the arches. i.e. for arches of the same curvature and covering the same span, the higher damping ratio along with severe reduction in the natural frequency, the high probability of damage occurrence.
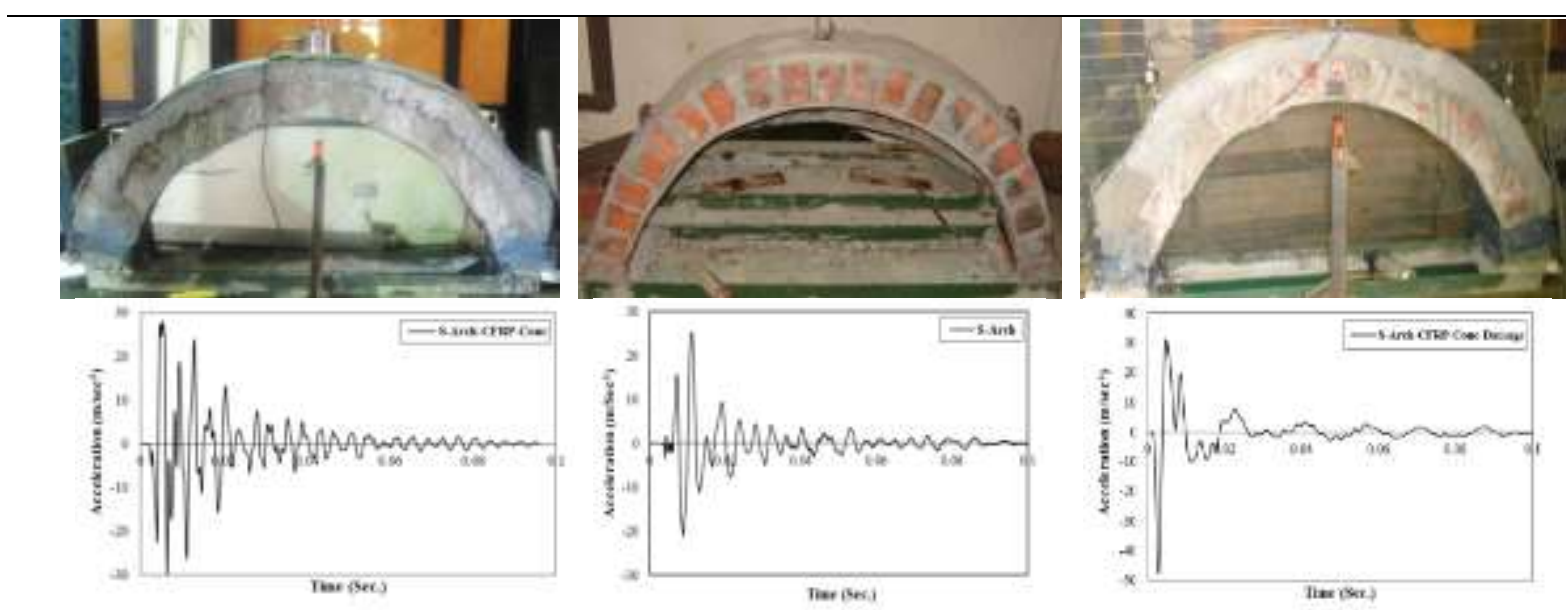

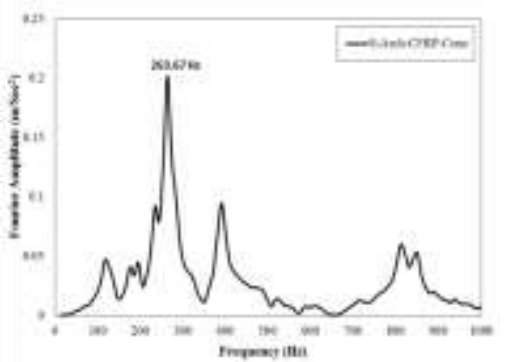

(a)

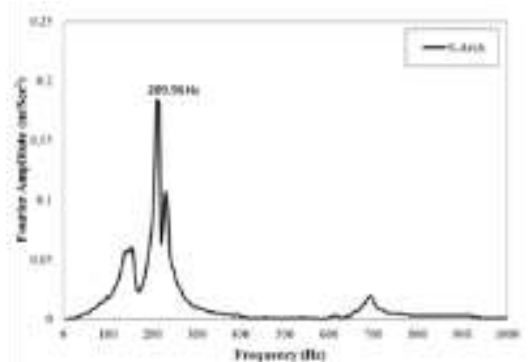

(b)

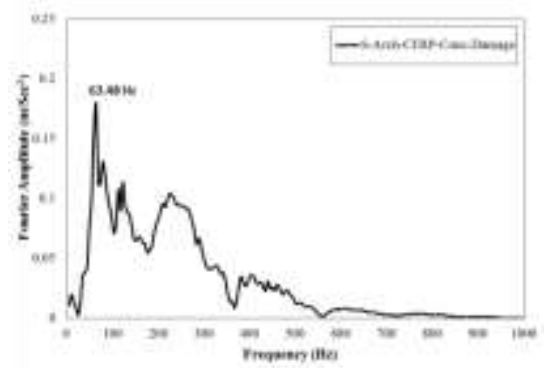

(c)

Figure 8: Shapes, Acceleration-Time Histories, and Corresponding FFT for: a) S-Arch-CFRP-Conc, b) $S$ Arch, and c) S-Arch-CFRP-Conc-Damage.

\subsection{Numerical}

The results of the numerical study were plotted in Figure 9 as a relation between 
the reduction in the global stiffness and the corresponding reduction in the frequency of the considered mode.

It can be noticed that the rate of change in the frequency value corresponding to a value of more than $50 \%$ reduction in the global stiffness, i.e. due to presence of severe damage, was much smaller than the case with damage causing reduction in global stiffness less than $50 \%$. The data was fitted by linear relation and presented in the same figure. The fitted data concluded that for $10 \%$ difference in global stiffness reduction $8.5 \%$ difference in fundamental frequency reduction will be occurred.

Considering the fitted data of the numerical analysis a chart was plotted to display the correlation between the experimental results and the numerical ones for all cases. Figure 10 displays the difference of the estimated values than the measured ones. Also, for the case of the same damage size that was occurred in three different locations, the results showed that the damage location affect the global stiffness more than the frequency change.

The average difference between experimental results and numerical one reaches to $23 \%$ while in case of different damage locations with the same size. The effect of location can cause change in stiffness reduction up to $13 \%$ with change in frequency reduction less than $2 \%$.

\section{CONCLUSIONS}

The investigated method to evaluate the damage in masonry arched structures was a powerful tool using a combination of dynamic modal testing, finite element analysis and monitoring of the change in the structure natural frequencies. The major conclusions of this research are:

- The Modal analysis technique is very practical technique, reliable, non-destructive and fast especially when global assessment is needed for the structures.

- The Modal analysis technique couldn't expect the damage reasons or locations.

- The higher the damping ratio, the higher probability of damage existence.

- For future research, it is suggested that this work may be enhanced by making a lot of field testing in addition to the analytical evaluation of many damage scenarios and boundary conditions.

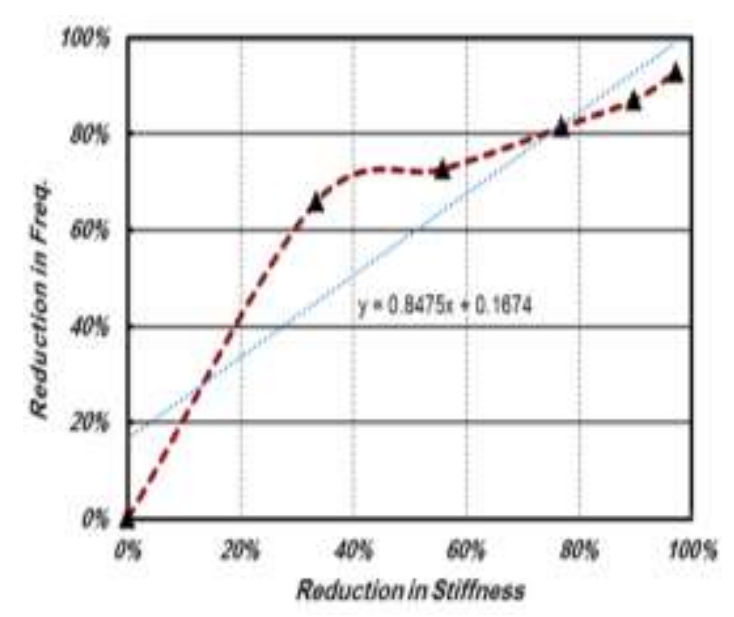

Figure 9: Relation between the Reduction in the Global Stiffness and Frequency

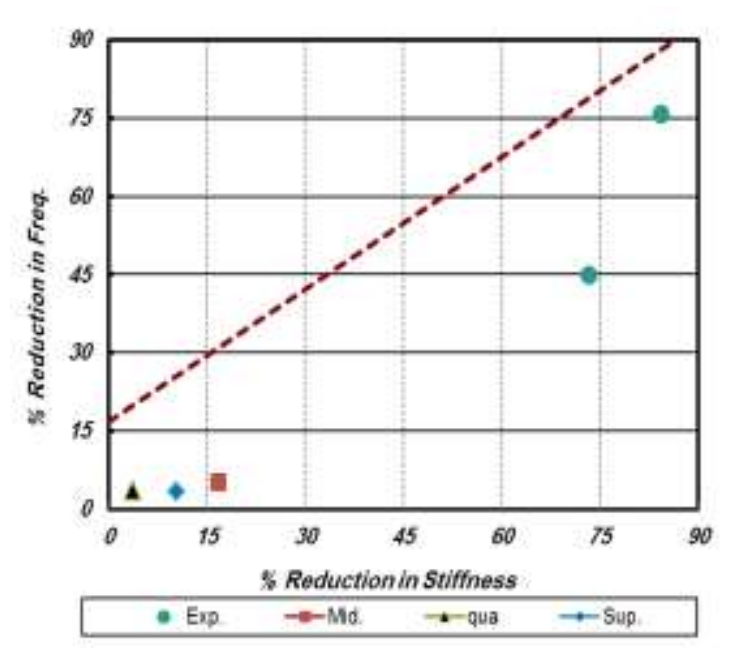

Figure 10: Correlation between Numerical and Experimental Results 


\section{REFERENCES}

[1] S. Salawu, and Clive Williams, "Bridge Assessment Using Forced Vibration Testing", Journal of Structural Engineering, ASCE, Vol. 121, No. 2, 1995, pp. 161-172.

[2] D. M. Armstrong, A. Sibbald and M.C. Forde, "Integrity Assessment of Masonry Arch Bridges Using the Dynamic Stiffness Technique" NDT \& E International, Vol. 28, No. 6, 1995, pp. 367-375.

[3] Patrick Paultre, Jean Proulx, Martin Talbot, "Dynamic Testing Procedures For Highway Bridges Using Traffic Loads" journal of structure engineering, ASCE, Vol. 121, No. 2, 1995, pp. 362-374.

[4] Muhammad, Halling, Womak, Nielson, "Forced Vibration Identification of Single - Span Bridge under Various Damage States", Transportation Research board, 1999.

[5] Ayman Khalil, El-Ghandour, "Vibrational Behavior of FRP Strengthened RC. Structures" the 3rd Middle East Symposium on Structural Composites for Infrastructure Applications, Aswan, Egypt, 2002.

[6] Wei-Xen Ren, Wael Zater, Issam E. Harik, "Ambient vibration-based seismic evaluation of a continuous girder bridge" Engineering Structures, Vol. 26, 2003, pp. 631-640.

[7] Ismet Calik, Alemdar Bayraktar, Temel Turker, Halil Karadeniz, "Structural dynamic identification of a damaged and restored masonry vault using Ambient Vibratons", Measurements, Vol. 55, 2014, pp. 462 - 472.

[8] Alemdar Bayraktar, Temel Turker, Ahmet Can Altunisik, "Experimental frequencies and damping ratios for historical masonry arch bridges", Construction and Buildings Materials, Vol. 75, 2015, pp. $234-241$.

[9] Ferit Cakir, Habib Uysal, "Experimental modal analysis of brick masonry arches strengthened prepreg composities", Journal of Cultural Heritage, Vol. 16, Issue 3, 2015, pp. 284-292.

[10] Wei Xie, Meirong Jiang, Hailong Chen, Jiannan Zhou, Ying $\mathrm{Xu}$, Peng Wang, Hualin Fan, Fengnian Jin, "Experimental behaviors of CFRP cloth strengthened buried arch structure subjected to subsurface localized explosion", Composite structures, Vol. 116, 2014, pp. $562-570$.

[11] SAP2000, User manual, Ver. 14.2.2, Computers and Structures, Inc., 2010. 